\title{
Case Report: Multiple Pulmonary Calssified Nodules and Cavitation Filled With the Dense Body on Chest X-Ray: A Case Report
}

\author{
Khosrow Agin $^{1 *}$ (D), Marymo Sadat Moin Azad Tehrani' ${ }^{1}$, Bita Dadpour ${ }^{2}$ (D), Maryam Vahabzadeh², Babak Mostafazadeh
}

1. Pulmonologist \& Pulmonary Critical Care, Logman Hakeem General Teaching hospital, Shahid Beheshti University of Medical Sciences, Tehran, Iran

2. Medical Toxicology Research Center, Mashhad University of Medical Sciences, Mashhad, Iran.

3. Toxicological Research Center, Shahid Beheshti University of Medical Sciences, Tehran, Iran.

\begin{tabular}{l|l}
$\begin{array}{l}\text { Use your device to san } \\
\text { and read the article online }\end{array}$ & $\begin{array}{l}\text { Crtation: Agin Kh, Moin Azad Tehrani MS, Dadpour B, Vahabzadeh M, Mostafazadeh B. Multiple Pulmonary Calssified } \\
\text { Nodules and Cavitation Filled With the Dense Body on Chest X-Ray: A Case Report. International Journal of Medical Toxicol- } \\
\text { ogy and Forensic Medicine. 2019; 9(4):255-260. https://doi.org/10.32598/ijmtfm.v9i4.25106 }\end{array}$ \\
dol' https://doi.org/10.32598/ijmtfm.v9i4.25106
\end{tabular}

\section{(c) (1) (s)}

Article info:

Received: 13 Apr 2019

First Revision: 25 Apr 2019

Accepted: 27 Aug 2019

Published: 01 Oct 2019

\section{Keywords:}

Chest x-ray, CT scan, Clacified pulmonary nodule, Cavitation, Aspergilloma, Mycobacterium tuberculosis

\section{ABSTRACT}

Imaging in the clinical study has a significant value in medical diagnosing and the following diseases. The characteristic signs of imaging are a clue in approach to differential diagnosis. A conventional chest $\mathrm{x}$-ray radiography is a more prevalent image used in the initial clinical assessment of pulmonary diseases. Iran is one of the 9 countries with a $95 \%$ burden of tuberculosis in the Eastern Mediterranian region. Chest radiography is the initial imaging for the evaluation of pulmonary tuberculosis.

\section{Introduction}

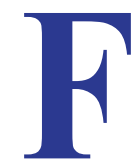

inding a nodule in lung radiography always suggests a decision whether this is a benign or malignant lesion and the next question is how to follow the lesion. The nodule character is very important in examining the nature of the nodule in the image. The calcification of a nodule alone is not a sufficient reason for differences between benign versus malignant lesions $[1,2]$. Computed Tomography (CT) scan and its various diagnostic techniques have been improved to a great extent in the diagnosis filed $[3,4]$. The prevalence of detection on nodule within the pulmonary parenchymal image is various and related to the selection of the image

\section{* Corresponding Author:}

Khosrow Agin, MD.

Address: Pulmonologist \& Pulmonary Critical Care, Logman Hakeem General Teaching hospital, Shahid Beheshti University of Medical Sciences,

Tehran, Iran.

Tel: +98 (912) 1170019

E-mail:agin@sbmu.ac.ir 
types. The distribution within the lung is more prevalent in lower than upper lobes [5].

\section{Case}

A 65-year-old male patient was presented in this study. The chief complain was dyspnea, which was associated with Functional class III. The clinical features had begun in the past week with progressive dyspnea accompanied by low-grade fever, cough, and sputum. He had had a history of admissions with recurrence dyspnea several times in the last 3 years. He had a history of heavy smoking and substance abuse for a long time.

Physical examination included $\mathrm{RR}=22$ per/minute, $\mathrm{PR}=120 \mathrm{per} /$ minute, $\mathrm{T}=38.5 \mathrm{C}$, and $\mathrm{BP}=170.90 \mathrm{mmHg}$. Laboratory results were as follow: $\mathrm{WBC}=5800, \mathrm{RBC}=3.6$, $\mathrm{Hgb}=11.7$, Creatinine $=0.9, \mathrm{ESR}=65 \mathrm{~mm}$, and $\mathrm{CRP}=38$. Arterial blood gas analysis consisted of $\mathrm{pH}=7.30$, $\mathrm{PaO}_{2}=31.4, \mathrm{PaCO}_{2}=54.4$, Sat $=54 \%$, and $\mathrm{Hco} 3=27.2$. The other lab parameters were HIV=negative, Hepatitis marker=positive, and CANCA and PANCA=negative. The induration of Purified Protein Derivative (PPD) was $8 \mathrm{~mm}$ and negative direct sputum smear of tuberculosis. The culture of tuberculosis was positive after 3 months. Aspergillus IgG antibody was 18.

The chest examination indicated low speech wheezing with central cyanosis. In addition, it was associated with general pitting edema with predominantly in lower extremity distribution.

Chest X-ray revealed hyperinflation in both lugs filed with the flatting diaphragm. Patchy infiltration was seen in the parenchymal lung displacement. A moderate size cavity was detected in the upper part of a lung zone that was filled with dense soft tissue. However, multiple low dense attenuated Calssified nodules detected on the chest radiography.

CT scan presented features of generalized emphysema and multiple nodules with Calssified rime in different sizes with approximately central micronodules calcifications. A cavity was manifested in the upper right lung with a thick layer that was occupied with a dense hyperlucent nodule in which associated with air crescent sign. It was placed within the reticular pattern background.

\section{Discussion}

CT scan revealed two morphologic features of nodules; pulmonary Calssified nodules and cavitary pulmonary nodules. Calssified pulmonary nodules differential diag- nosis is suggested as follows. Table 1 shows a differential diagnosis of Calssified pulmonary nodules [6].

A pulmonary nodule is defined as an abnormal parenchymal lung lesion with a diameter of $10 \mathrm{~mm}$ to $30 \mathrm{~mm}$, which is surrounded by the normal lung parenchyma without the accompaniment of adenopathy or atelectasis. It is found in $2 \%$ of standard chest radiographs and $8 \%$ to $51 \%$ of CT scans [7].

The Calssified pulmonary nodule is the manifestation reaction of the immune system to the foreign body. Any external material can be cleaned to be distracted by enzymatic functions or being wall-masonry with calcify matter enclosed within the nodule. However, this mechanism also applies to the organisms sich as tuberculosis, fungus, etc.

The calcification of a nodule can greatly increase the likelihood of a benign lesion. Carcinoma can also have a similar clinical picture such as primary central carcinoid, primary bronchogenic carcinoma, association with a malignant tumor and granuloma, and the changes of dystrophic calcification within the tumor and metastasis [8].

The differential diagnosis between benign and malignant pulmonary nodules is based on the medical history, volume, or growth rate of the nodule in a long time [9] and imaging study for the characteristic morphologic nodule [10].

Clinical judgment requires attention to epidemiological factors, including age, smoking habits, and associated diseases. The likelihood of malignancy has a reverse relationship with age. It increased by up to $88 \%$ in ages older than 70 years. A positive medical history supports the high probability of risk factors of malignancy such as smoking habit, exposure to the hazardous substances (Asbestosis), the presence of malignant disease in history, and HIV infection [7].

The sensitivity and specificity of CT scan are $94 \%$ to $96 \%$ and $72 \%$ to $99 \%$ for follow-up evaluation, respectively [11]. Image size, context, attenuation CT, margination, and content of nodules are important in CT scan surveillance [12]. The threshold size of nodules $<3$ to 5 $\mathrm{mm}$ is less likely to be considered for malignancy. Context nodule is associated with solid ( $>4 \mathrm{~mm}$ ), ground glass ( $>20 \mathrm{~mm})$, partially solid [13] look more closely at the possibility of malignancy.

Pulmonary nodule calcifications follow 6 patterns; central dense nidus, diffuse solid, laminated, popcorn, 
Table 1. Differential diagnoses of calssified pulmonary nodules

\begin{tabular}{|c|c|}
\hline Diseases Associated With Calcified Nodule & Cases \\
\hline Healed infection & $\begin{array}{l}\text { Calssified granuloma as thoracic histoplasmosis } \\
\text { Healed varicella pneumonia }\end{array}$ \\
\hline Pneumoconiosis & Silicosis, coal workers' pneumoconiosis \\
\hline Pulmonary hamartoma & - \\
\hline Metastatic pulmonary calcification & Chronic renal failure, multiple myeloma, secondary hyperparathyroidism \\
\hline Pulmonary haemosiderosis & Idiopathic pulmonary haemosiderosis, mitral stenosis, Goodpasture \\
\hline Pulmonary alveolar microlithiasis & - \\
\hline Sarcoidosis & - \\
\hline Pulmonary hyalinizing granuloma & - \\
\hline Calssified pulmonary metastases & Osteosarcoma \\
\hline Calssified fibrous pseudotumor of lung & - \\
\hline
\end{tabular}

punctate, and dendriform. Granuloma and popcorn lesions have the patterns of central diffuse and laminated and most should be considered benign. Hounsfield unit attenuation or CT numbers may be effective in diagnosis. Numbers over $200 \mathrm{HU}$ are favor of the calcification, although the specificity of $98 \%$ and sensitivity of $66 \%$ are not desirable. The indeterminate pulmonary nodule is up to $30 \mathrm{~mm}$ in size and has more malignant features (45\%-90\%) [11].

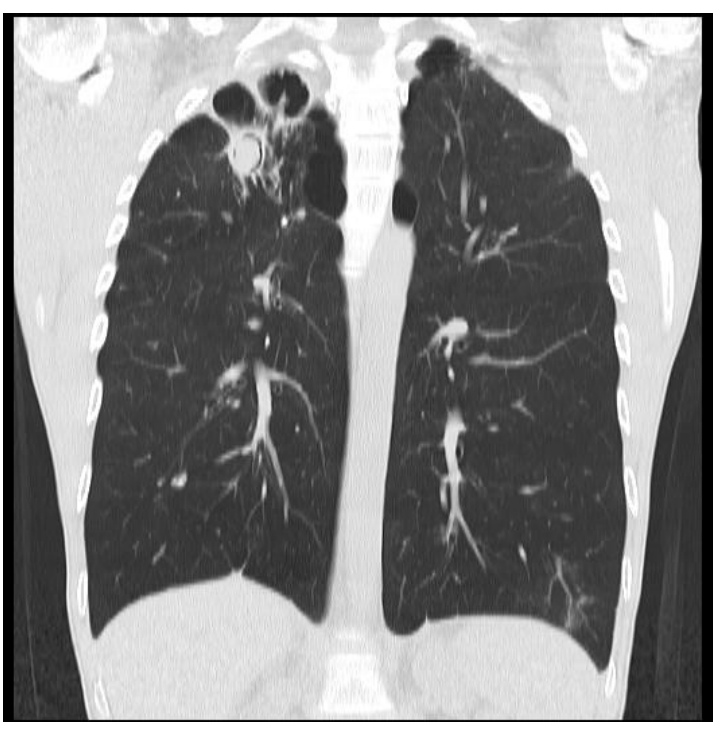

International Journal of

Figure 1. The plain of CT scan with cavitary with dense body
The margin of the nodule is suggestive for characteristic but not diagnostic lesions. It includes corona radiata, lobulated, smooth contour, and satellite; the recent margin shape presents the highly benign etiology. The contents of the nodule can also be effective in the differential diagnosis. Air bronchogram and air-fluid levels are the cardinal features that can be seen in the CT scans. Air bronchogram sign reveals lymphoma, adenocarcinoma, sarcoidosis, and round pneumonia. The air-fluid level within nodule may disclose tumor necrosis.c

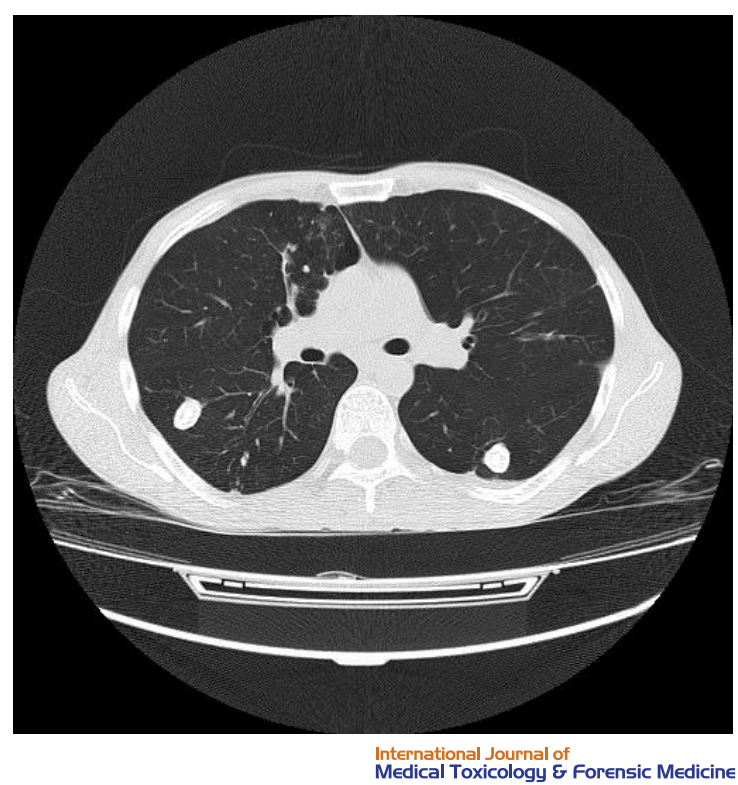

Figure 2. The plain of CT scan with multiple calssified nodules 


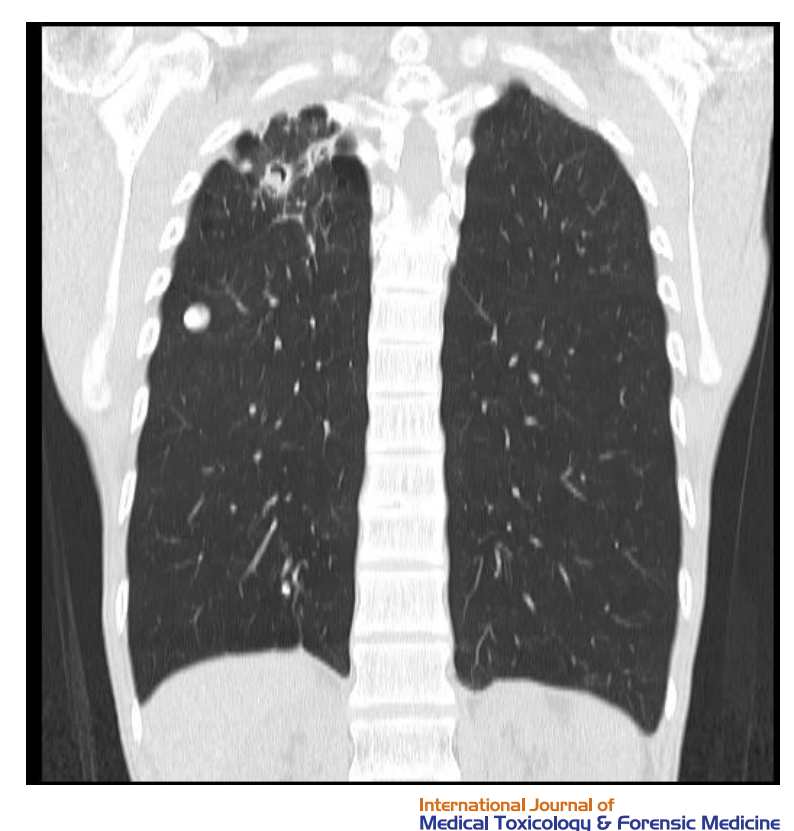

Figure 3. The plain of CT scan with multiple cavity in upper lobe with dense body and calssified nodules

The cavitation is one of the radiographic signs. The cavitation is characterized by two specificities in terms of the diagnosis filed; the amount of wall thickness and its contents. The walls of more than $1.5 \mathrm{~mm}$ is likely to be mostly malignant. The texture may be associated with the air-fluid level and or dense body [14]. Figures 1,2 and 3 show different features of the cavitary and dense body.

A cavitating lung nodule is another term that is used for a different diagnosis. The causes include infectious tuberculosis, septic emboli, echinococcosis and non-infectious as granulomatosis with polyangiitis, hematogenous metastasis, pulmonary embolism, lymphomatous granulomatosis, pulmonary Langerhans cell histiocytosis, primary bronchogenic carcinoma, pulmonary lymphoma, and sarcoidosis [15].

Aspergilloma is a fungus ball of Aspergillus fumigatus (A. fumigatus). It grows within the preexisting cavities of lung parenchyma and has the tendency to grow in the cavity created by tuberculosis in the lung [16]. The classic feature of aspergilloma in the lung is a cavity filled with a fungus ball. An air crescent shadow separates fungus ball from the wall of the cavity (Monod's sign). It is manifested in hydatid cyst, Wegener's granulomatosis, hematoma, and abscess [17]. Week seroconversion of the IgG aspergillosis antibody was suggested to the chronic aspergillosis. Tuberculosis infection and aspergilloma is a rare association [18].
A number of differential diagnoses may be discarded because of non-compliance with patient information. They are presented in Table 1.

\section{Ethical Considerations}

\section{Compliance with ethical guidelines}

All ethical principles were considered in this article. The participants were informed about the purpose of the research and its implementation stages; they were also assured about the confidentiality of their information; Moreover, They were allowed to leave the study whenever they wish, and if desired, the results of the research would be available to them.

\section{Funding}

This research did not receive any specific grant from funding agencies in the public, commercial, or not-forprofit sectors.

\section{Author's contributions}

Providing the patient information: Maryam Moin Azad Tehrani; Performing, writing and editing the article: Khosrow Agin.

\section{Conflict of interest}

The authors declared no conflict of interest.

\section{References}

[1] Berger WG, Erly WK, Krupinski EA, Standen JR, Stern RG. The solitary pulmonary nodule on chest radiography: Can we really tell if the nodule is calssified? American Journal of Roentgenology. 2001; 176(1):201-4. [DOI:10.2214/ ajr.176.1.1760201] [PMID]

[2] van't Westeinde SC, de Koning HJ, Xu DM, Hoogsteden HC, van Klaveren RJ. How to deal with incidentally detected pulmonary nodules less than $10 \mathrm{~mm}$ in size on CT in a healthy person. Lung Cancer. 2008; 60(2):151-9. [DOI:10.1016/j.lungcan.2008.01.020] [PMID]

[3] Roos JE, Paik D, Olsen D, Liu EG, Chow LC, Leung AN, et al. Computer-Aided Detection (CAD) of lung nodules in CT scans: Radiologist performance and reading time with incremental CAD assistance. European Radiology. 2010; 20(3):549-57. [DOI:10.1007/s00330-009-1596-y] [PMID] [PMCID]

[4] Toghiani A, Adibi A, Taghavi A. Significance of pulmonary nodules in multi-detector computed tomography scan of noncancerous patients. Journal of Research in Medical Sciences. 2015; 20(5):460-4. [DOI:10.4103/1735-1995.163967] [PMID] [PMCID] 
[5] Renne J, Linderkamp C, Wacker F, Berthold LD, Weidemann J. Prevalence and configuration of pulmonary nodules on multi-row CT in children without malignant diseases. European Radiology. 2015; 25(9):2651-6. [DOI:10.1007/s00330015-3675-6] [PMID]

[6] Radiopaedia. Calssified pulmonary nodules [Internet]. 2019 [Updated 2019 nov 16]. Available from: https://radiopaedia. org/articles/Calssified-pulmonary-nodules

[7] Furman AM, Dit Yafawi JZ, Soubani AO. An update on the evaluation and management of small pulmonary nodules. Future Oncology. 2013; 9(6):855-65. [DOI:10.2217/fon.13.17] [PMID]

[8] Khan AN, Al-Jahdali $\mathrm{HH}$, Allen CM, Irion $\mathrm{KL}$, Al Ghanem S, Koteyar SS. The Calssified lung nodule: What does it mean? Annals of Thoracic Medicine. 2010; 5(2):67-79. [DOI:10.4103/1817-1737.62469] [PMID] [PMCID]

[9] Petkovska I, Brown MS, Goldin JG, Kim HJ, McNitt-Gray MF, Abtin FG, et al. The effect of lung volume on nodule size on CT. Academic Radiology. 2007; 14(4):476-85. [DOI:10.1016/j.acra.2007.01.008] [PMID] [PMCID]

[10] Sayyouh M, Vummidi DR, Kazerooni EA. Evaluation and management of pulmonary nodules: State-of-the-art and future perspectives. Expert Opinion on Medical Diagnostics. 2013; 7(6):629-44. [DOI:10.1517/17530059.2013.858117] [PMID]

[11] Gierada DS, Pilgram TK, Ford M, Fagerstrom RM, Church TR, Nath H, et al. Lung cancer: Interobserver agreement on interpretation of pulmonary findings at low-dose CT screening. Radiology. 2008; 246(1):265-72. [DOI:10.1148/radiol.2461062097] [PMID]

[12] Rubin GD. Lung nodule and cancer detection in computed tomography screening. Journal of Thoracic Imaging. 2015; 30(2):130-8. [DOI:10.1097/RTI.0000000000000140] [PMID] [PMCID]

[13] Clark TJ, Flood TF, Maximin ST, Sachs PB. Lung CT screening reporting and data system speed and accuracy are increased with the use of a semiautomated computer application. Journal of the American College of Radiology. 2015; 12(12):1301-6. [DOI:10.1016/j.jacr.2015.07.015] [PMID]

[14] Truong MT, Ko JP, Rossi SE, Rossi I, Viswanathan C, Bruz$\mathrm{zi}$ JF, et al. Update in the evaluation of the solitary pulmonary nodule. Radiographics. 2014; 34(6):1658-79. [DOI:10.1148/ rg.346130092] [PMID]

[15] Madan K, Purkait S, Arava S, Bhalla AS, Kumar R, Guleria R. A 79-year-old woman with bilateral cavitating lung nodules. Chest. 2014; 145(6):1419-24. [DOI:10.1378/chest.13-2081] [PMID]

[16] Prasad BP, Ray B. Singular observation of a desirable change after bronchial artery embolization for hemoptysis in intracavitary aspergilloma. The Indian Journal of Radiology \& Imaging. 2017; 27(2):225-8. [DOI:10.4103/ijri.IJRI_335_16] [PMID] [PMCID]

[17] Ofori A, Steinmetz AR, Akaasi J, Asafu Adjaye Frimpong GA, Norman BR, Obeng-Baah J, et al. Pulmonary aspergilloma: An evasive disease. International Journal of Mycobacteriology. 2016; 5(2):235-9. [DOI:10.1016/j.ijmyco.2016.03.002] [PMID]
[18] Singh H. Aspergilloma in a patient with a history of TB. BMJ Case Reports. 2014; 2014:pii:bcr2013203276. [DOI:10.1136/ bcr-2013-203276] [PMID] [PMCID] 
This Page Intentionally Left Blank 